\title{
Esthetic preference as a function of pattern information
}

DONALD D. DORFMAN

SAN DIEGO STATE COLLEGE

\begin{abstract}
Abstraet
This study tested the hypothesis that pattern preference is a function of the informational value of a set of patterns where information is manipulated by varying matrix grain. The results showed an inverse- $U$ relation between information and preference. These results agreed with the findings of Munsinger \& Kessen (1964) who varied the coordinality of the patterns rather than matrix grain.
\end{abstract}

\section{Problem}

Several authors (Attneave, 1959; Berlyne, 1957; Dember \& Earl, 1957) have suggested that esthetic preference depends upon the informational value or uncertainty of the patterns being judged. Munsinger \& Kessen (1964) have recently obtained evidence supporting this hypothesis with a class of figures in which uncertainty was manipulated by varying the coordinality of the stimulus. They obtained evidence of an inverse-U relation between uncertainty and pattern preference. Another way of varying amount of information or uncertainty of a set of patterns is to vary the grain of the displays. The present study attempts to determine if the conclusions reached by Munsinger \& Kessen (1964) on coordinality of the stimulus also hold when the grain of the patterns is varied.

\section{Method}

The Ss were 100 girls enrolled in Introductory Psychology. Two Viewlex projectors were used to present pairs of patterns on 2 in $x 2$ in slides. An attachment to the projectors permitted the projection of two patterns simultaneously and side by side. The exposure time for the pair of patterns was $7 \mathrm{sec}$.

The patterns were constructed from $\mathrm{N} \times \mathrm{N}$ matrix grains where $\mathrm{N}$ equalled $2,4,6,8,10$, or 12 . Each cell within a matrix grain was made either green or white, with the probability of a green or white cell set at .50 and determined by a table of random numbers. The green was $5 \mathrm{G} 5 / 8$ in the Munsell notation. Four groups of patterns were constructed. Each group contained six patterns, one instance of each of the six grains. Figure 1 shows a group of six patterns constructed in this fashion. Overall, there were 24 patterns, six matrix grains and four instances of each grain. Adopting the Shannon-Wiener measure of information, this resulted in six classes of patterns, each class having an average of $4,16,36,64,100$, or 144 bits of information. The pattern space of each matrix grain consisted of the set of all possible patterns generated from the matrix, with all patterns being equally probable.

The method of paired comparisons was used to obtain subject preferences. The Ss were given all pos-
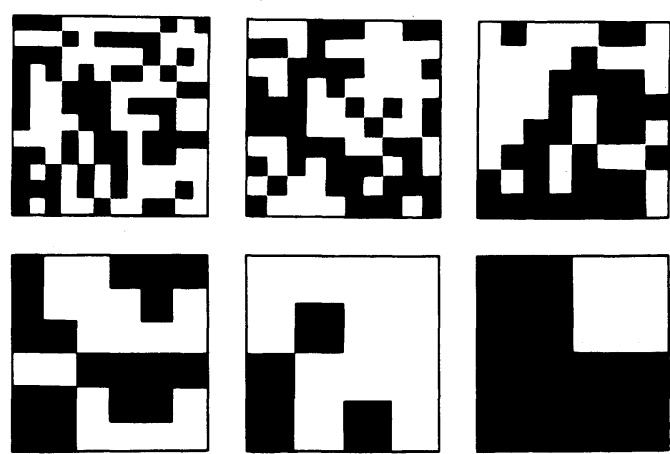

Fig. 1. Six patterns, each constructed from a different matrix grain.

sible pairs of patterns within each group (15 pairs for each group of 6) and were asked to choose the pattern they preferred of the pair. Paired-comparisons data were obtained on the four groups of patterns in succession. Order of presentation and pattern position were randomized across Ss. The instructions were as follows: "You will be shown 60 pairs of patterns, a pair at a time, side-by-side on the screen. Each pair will be exposed for only $7 \mathrm{sec}$., no longer. With $L$ representing the pattern on the left and $R$ the pattern on the right, check either $\mathbf{L}$ or $\mathbf{R}$ with an $\mathrm{X}$ alongside each number for the pattern you prefer. There are no right or wrong answers. Just designate the pattern you prefer of each pair. If you have any questions, raise your hand."

The Ss were run in groups of 2 to 10 and their responses were recorded on response-sheets given to them.

\section{Results and Diseussion}

The total percentage of times that each $\mathrm{S}$ chose a particular matrix grain was obtained for the four groups

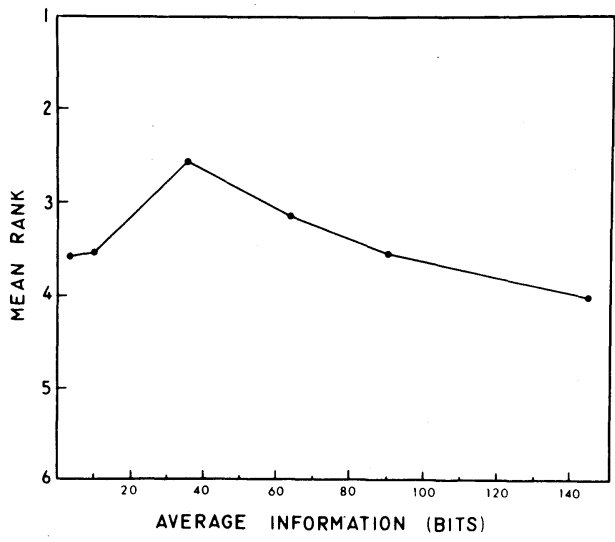

Fig. 2. Mean rank as a function of the informational value of each pattern class. 

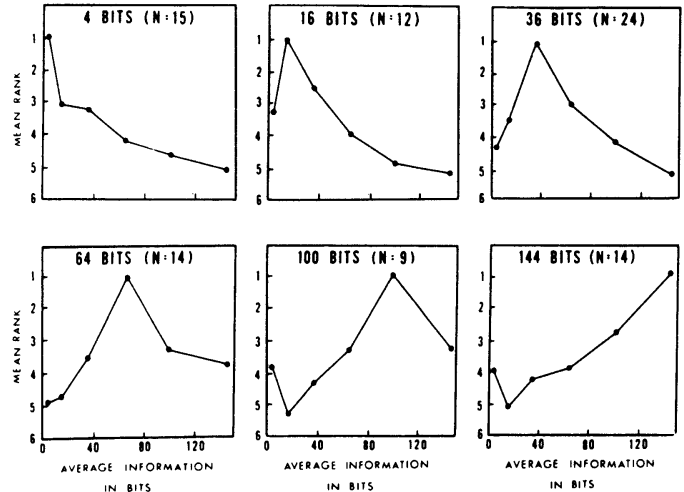

Fig. 3. Mean rank as a function of pattern information, where each group of Ss is separated according to the most preferred level of information.

of six matrix grains, and these percentages were rankordered. The mean ranks for the six matrix grains averaged over Ss are presented in Fig. 2. As can be seen, the results show an inverse-U relation between the informational level of each class and mean rank. These data agree with the findings of Munsinger \& Kessen (1964) in which they manipulate information by varying the coordinality of the patterns. Consequently, their findings relating information to pattern preference may now be extended to patterns which vary in matrix grain. A Friedman analysis of variance performed on these data showed a highly significant $\mathrm{X}_{\mathrm{r}}^{2}\left(\mathrm{X}_{\mathrm{r}}^{2}=57.35\right.$; $\mathrm{df}=5 ; \mathrm{p}<.001$ ). It has also been suggested that each $\mathrm{S}$ has some preferred level of information (Dember \& Earl, 1957), and that preference for other levels of information will decrease as the distance of a pattern from this preferred level increases. Figure 3 shows the Ss separated according to their most preferred level of information among the six possible levels. Eleven of the Ss had ties at the first rank and therefore were excluded. A Friedman analysis of variance performed on these data showed highly significant effects in all six groups $(p<.001, d f=4$ in all cases). The null hypothesis was that the set of ranks in each of the five classes (excluding the most preferred class) represented a random sample from a rectangular distribution. Figure 3 shows that the order predicted by Dember and Earl held in all groups except that in the groups for whom 100 bits and 144 bits were most preferred, there was a slight rise in preference for the class having the lowest level.

\section{References}

Attneave, F. Applications of information theory to psycholor. New York: Holt, 1959.

Berlyne, D. E. Uncertainty and conflict: A point of contact between information-theory and behavior-theory concepts. Psychol. Rev., 1957, 64, 329-339.

Dember, W. N., \& Earl, R. W. Analysis of exploratory, manipulatory, and curiosity behaviors. Psychol. Rev., 1957, 64, 91-96.

Munsinger, H., \& Kessen, W. Uncertainty, structure, and preference. Psychol. Monogr., 1964, 78, No. 586. 